\title{
Evaluation of constitutive models for textured aluminium alloys using plane-strain tension and shear tests
}

\author{
Dasharatha Achani • Odd-Geir Lademo • Olaf Engler • \\ Odd Sture Hopperstad
}

Received: 5 May 2010 / Accepted: 9 February 2011 /Published online: 5 March 2011

(C) The Author(s) 2011. This article is published with open access at Springerlink.com

\begin{abstract}
The constitutive modelling of the strongly textured aluminium alloys AA6063-T6 and AA7003-T6 is studied. The materials were delivered in the form of flat extruded profiles. Plane-strain tension and shear tests in the plane of the flat profiles are performed. The tests are then used to evaluate a constitutive model including an anisotropic yield function, the associated flow rule and a nonlinear isotropic work-hardening rule. The parameters of the yield criterion and the work-hardening rule were identified primarily from uniaxial tension tests in different in-plane directions. It is suggested how analytical considerations and the results from the plane-strain tension and shear tests may be used to obtain a more accurate calibration of the anisotropic yield criterion. To further assess the constitutive model, finite element simulations of the plane-strain tension and shear tests are carried out and the results compared with the experimental force-elongation curves. Significant deviations in the experimental and predicted results are disclosed, and attributed partly to the parameter identification, primarily based on uniaxial tension tests, and partly to the assumption of isotropic work-
\end{abstract}

D. Achani · O.-G. Lademo $(\bowtie) \cdot$ O. S. Hopperstad

Structural Impact Laboratory (SIMLab), Centre for Research-

based Innovation and Department of Structural Engineering,

Norwegian University of Science and Technology,

NO-7491 Trondheim, Norway

e-mail: odd-geir.lademo@sintef.no

O.-G. Lademo

SINTEF Materials and Chemistry,

Applied Mechanics and Corrosion,

NO-7465 Trondheim, Norway

O. Engler

Hydro Aluminium Rolled Products GmbH, R\&D Center Bonn, P.O. Box 2468, 53014 Bonn, Germany hardening. Polycrystal plasticity calculations are carried out for simple shear of the AA7003-T6 material, indicating that texture evolution plays an important role in determining the response in this test already at moderate strains.

Keywords Aluminium alloys · Plastic anisotropy · Yield function P Polycrystal plasticity calculations

\section{Introduction}

Within the automotive industry, safety, environmental concerns, economy and structural reliability are constant driving forces for innovation of new products and processes. At the same time economy forces the industry to reduce their product cycles, which in turn reduces time for design and development. In order to meet these challenges, large-scale Finite Element (FE) simulations are systematically used in the product development to obtain cost efficient and optimized solutions. Even though non-linear FE codes are routinely used and considered as indispensable tools, it is a well-known fact that the predictive capability of these codes depends strongly on the accuracy of the constitutive models used to describe the material behaviour. Full-scale analyses, either of a forming operation or a crash event, require large FE models and simulations involving large plastic deformations. Hence, it is important that the constitutive model is not only accurate but also efficient and robust. Since the models are to be used in an industrial context, parameter identification through simple tests is also important.

Extruded aluminium alloys exhibit strong anisotropy in the plastic properties due to the extrusion process [1-8]. The anisotropy differs between recrystallized alloys and fibrous, non-recrystallized alloys, owing to the differences in microstructure [7]. For structural analysis of extruded 
aluminium alloy components, e.g. in FE simulation of formability, plastic forming and crashworthiness, constitutive models accounting for the plastic anisotropy have been used in several studies [9-14]. Over the years, many phenomenological yield criteria have been proposed, attempting to represent the plastic anisotropy observed in metals and alloys, e.g. [15-24]. In a previous study by some of the authors [25], the behaviour of the extruded aluminium alloys AA7003-T6 and AA6063-T6 under proportional and non-proportional strain paths was studied. Uniaxial tension tests in different in-plane directions were carried out for as-received profiles and profiles pre-strained in uniaxial tension. Both alloys were found to be strongly anisotropic with respect to strength, plastic flow and elongation. The plastic anisotropy differs between the two alloys owing to the different grain morphology and crystallographic texture. Two linear transformation-based anisotropic yield functions were evaluated for the alloys. It was found that the Yld2004-18p yield function proposed by Barlat et al. [24] accurately represented the experimental data for both alloys.

In this paper, the constitutive model for the extruded aluminium alloys AA7003-T6 and AA6063-T6 (as established by Achani et al. [25]) is evaluated by means of plane-strain tension and shear tests. The chosen tests are simple and inexpensive to perform in a standard test machine, but they do not provide neither ideal nor homogeneous stress states. Direct use of such experimental data for parameter identification purposes may thus be inaccurate. Therefore we do not aim to identify stress-strain characteristics from these tests. Instead we search for the force-deformation characteristics, and qualitative information about the relative directional strength under these test conditions. The force-deformation curves are utilised for FEbased evaluation of the constitutive equations and parameters, while we explore how the relative directional strengths may be used in the parameter identification process. In addition to the anisotropic yield function Yld2004-18p, the constitutive model assumes the associated flow rule and a nonlinear isotropic work-hardening rule. The plane-strain tension and shear tests are carried out for three orientations with respect to the extrusion directions to reveal the plastic anisotropy in strength, work-hardening and elongation. It is suggested how analytical considerations together with the results from the plane-strain tension and shear tests may be used to obtain a more accurate calibration of the anisotropic yield criterion. The possible use of plane-strain tension and shear tests to characterize the stress-strain behaviour of metallic materials and to identify the parameters of elastic-plastic constitutive equations has been proposed in several studies, e.g. [26-29]. To further evaluate the constitutive model for the extruded aluminium alloys, finite element simulations of the planestrain tension and shear tests are carried out and the results compared with the experimental force-elongation curves. To investigate the influence of texture evolution on the obtained results, polycrystal plasticity calculations were conducted.

\section{Experimental}

\section{Materials}

The materials were received as flat extruded profiles in temper T6, which is the peak hardness condition. The extruded profiles had a rectangular cross section of $2 \mathrm{~mm}$ thickness and $200 \mathrm{~mm}$ width (nominal values). Temper T6 is obtained by solution heat treatment after extrusion and then artificial aging at elevated temperatures for time periods specific to each alloy. The chemical composition and grain structures of the investigated materials are presented by Achani et al. [25]. The AA7003-T6 material has a non-recrystallized and fibrous grain structure, whereas the grain structure of AA6063-T6 is recrystallized and equiaxed.

The crystallographic texture of the two Al alloys were measured by means of electron back-scatter diffraction (EBSD) and used to calculate the three-dimensional orientation distribution function (ODF) $f(g)$ [30]. In both alloys, EBSD maps were recorded in the longitudinal section in order to integrate texture over all thickness layers. The ODF calculations were performed under the assumption of orthotropic sample symmetry - given by the extrusion direction (ED), the transverse direction (TD) and the normal direction (ND) of the profiles - such that Euler angles are in the domain $0^{\circ} \leq\left\{\phi_{1}, \Phi, \phi_{2}\right\} \leq 90^{\circ}$. The texture of alloy AA7003-T6 is characterized by a strong Bsorientation $\{011\}<211>$ which is found in the ODF at $\left\{\phi_{1}, \Phi, \phi_{2}\right\}=\left\{35^{\circ}, 45^{\circ}, 0^{\circ} / 90^{\circ}\right\}$, see Fig. 1 (left). This is consistent with the observation of a fibrous, nonrecrystallized microstructure in this material. The ODF of alloy AA6063-T6 displays a quite sharp cube texture with pronounced scatter about the ED, see Fig. 1 (right), which is typical of recrystallized material (e.g. [7]).

\section{Plane-strain tension tests}

The geometry of the plane-strain tension specimen should be such that the specimen subjected to tension should yield with zero contraction in the width direction. In practice, this is difficult to obtain. Here the geometry shown in Fig. 2 (top) is chosen. Since the experimental data will be compared with finite element simulations, the actual value of the transverse strain is of little importance as long as the stress state obtained is sufficiently different from uniaxial tension. The specimens were clamped at each end and tested in an MTS 110 uniaxial testing machine at a 

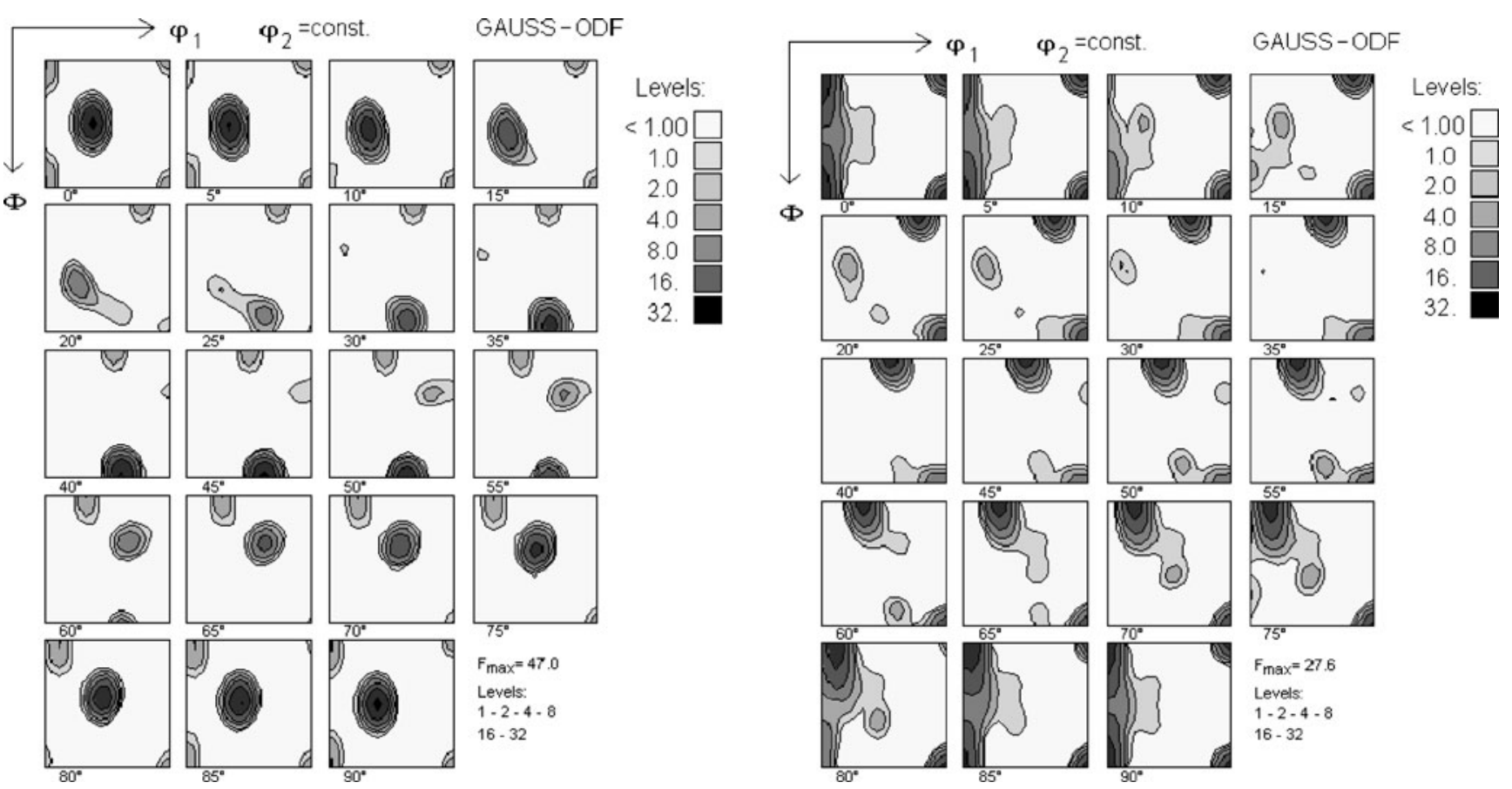

Fig. 1 Orientation distribution function (ODF) for AA7003-T6 (left) and AA6063-T6 (right)
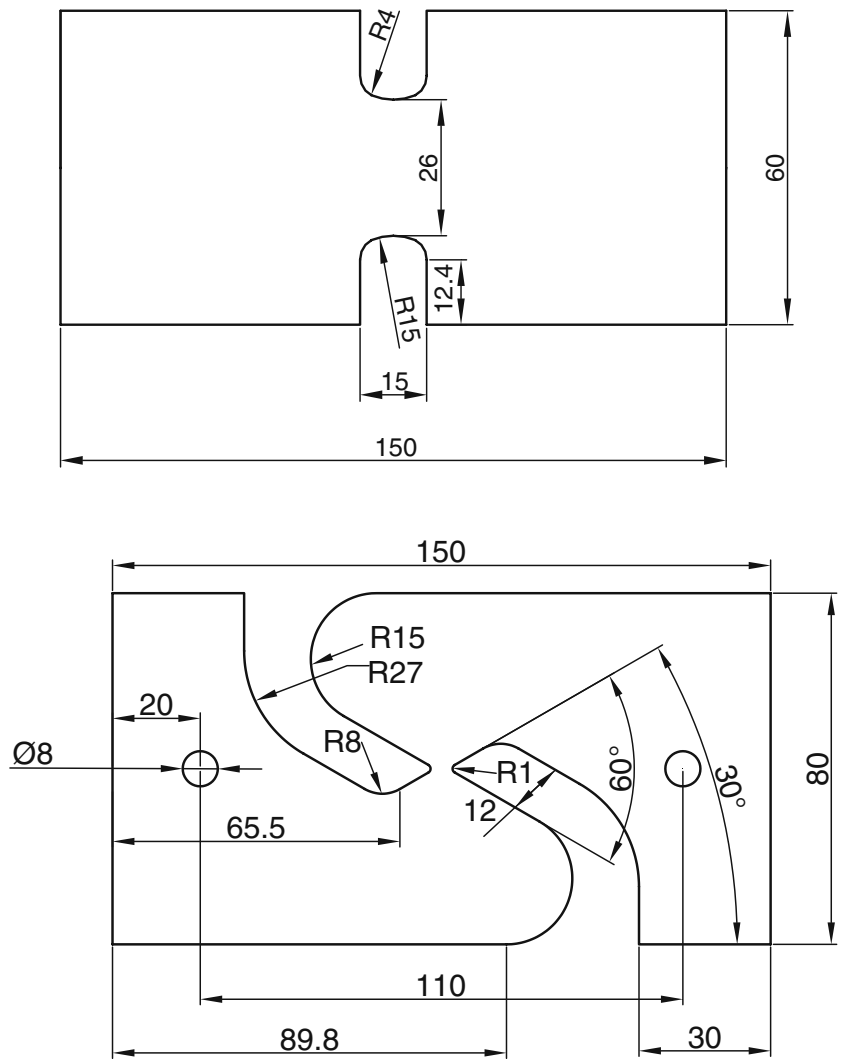

Fig. 2 Geometry of test specimens (measures in $\mathrm{mm}$ ): plane-strain tension (top) and in-plane shear (bottom) displacement velocity of $1 \mathrm{~mm} / \mathrm{min}$. An extensometer with a $25 \mathrm{~mm}$ gauge length was attached to measure the longitudinal deformation of the centre region. The force and the elongation of the extensometer gauge were continuously recorded during testing.

Duplicate tests were performed in the $0^{\circ}, 45^{\circ}$ and $90^{\circ}$ directions for both materials. Fig. 3 (left) and Fig. 4 (left) present in turn the results for AA7003-T6 and AA6063-T6 as nominal stress $s=F / A_{0}$ versus elongation $\Delta L_{g}$, where $F$ is the applied force, $A_{0}$ is the initial area of the minimum cross section in the gauge area and $\Delta L_{g}$ is the elongation within the extensometer gauge length. With one exception, the scatter in the experimental data is insignificant. The exception was the $0^{\circ}$ direction for AA6063-T6 where some scatter was observed [31].

As with the uniaxial tensile tests, reported by Achani et al. [25], these tests also demonstrate the strong anisotropy of the materials. It is noted that for plane-strain tension, the force is highest in the $90^{\circ}$ direction and lowest in the ED for both the investigated materials. The ultimate force in these tests corresponds to the onset of necking. It is evident that the elongation at ultimate force depends upon orientation. In particular, the $90^{\circ}$ specimens demonstrate less elongation at ultimate force than the other directions.

In-plane shear tests

The specimen proposed by Lademo et al. [32] and schematically depicted in Fig. 2 (bottom) is adopted for the shear testing. The geometry of the shear specimen is 

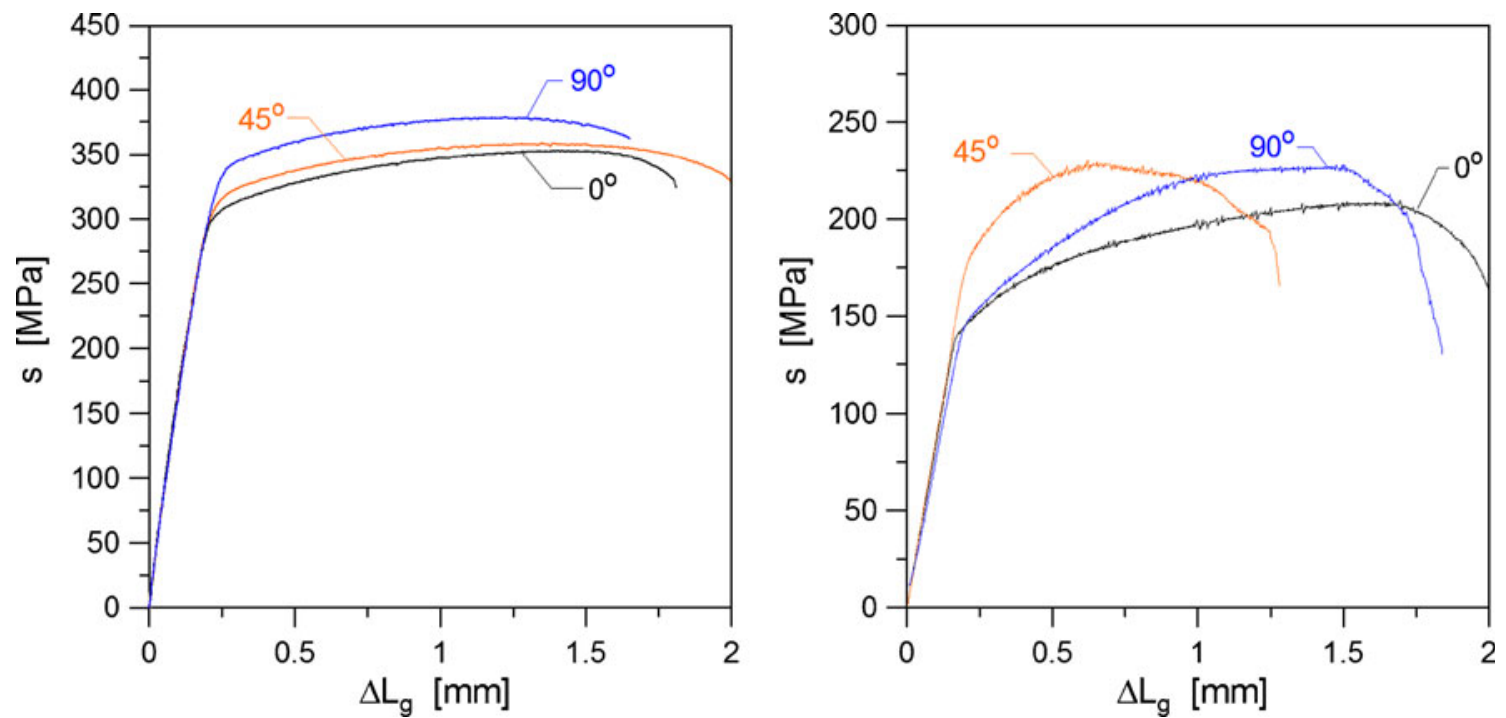

Fig. 3 Nominal stress versus elongation of extensometer gauge in plane-strain tension tests (left) and shear tests (right) of AA7003-T6

designed to have a small and concentrated shear-zone with a gauge length of $5 \mathrm{~mm}$ and upon loading the gauge section will be subjected to pre-dominant shear deformation. The specimen further consists of two notches in $60^{\circ}$ angle having a small radius. Each end section of the specimen is designed with a hole to facilitate loading through a bolt. The horizontal axis of these holes lies along the central longitudinal axis of the specimen. The specimens can, alternatively, be clamped by the hydraulic grips of the test machine.

The tests were performed under quasi-static conditions in an Instron (8500/8800) testing machine with a $10 \mathrm{kN}$ load cell. To get a well defined deformation measurement across the shear-zone, an extensometer with a $75 \mathrm{~mm}$ gauge length was attached to the specimen. For the duration of the

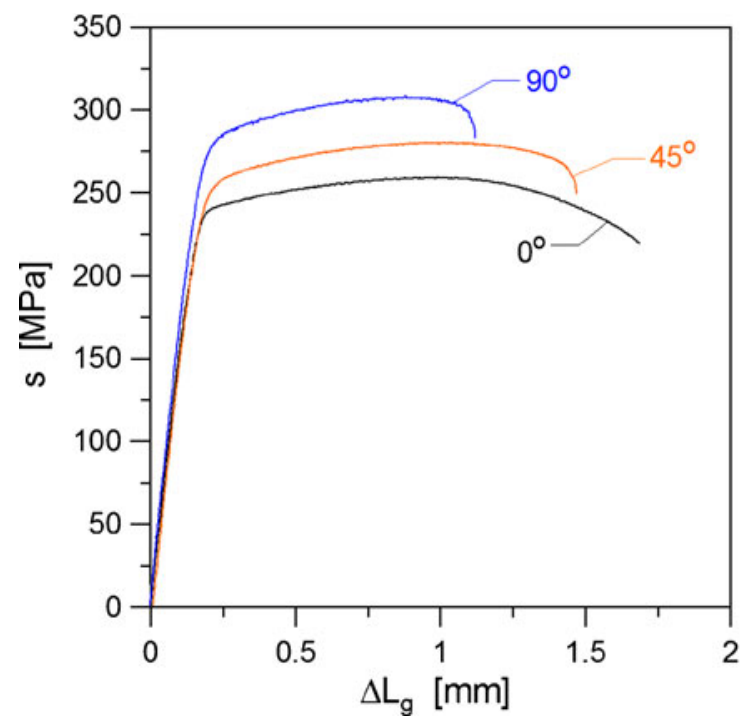

test, the applied force and the elongation of the extensometer gauge along the loading axis were continuously recorded. For all specimens, the crosshead displacement rate was set to 0.6 $\mathrm{mm} / \mathrm{min}$.

Three parallel tests were performed in three directions for each of the materials AA7003-T6 and AA6063-T6. For AA7003-T6 the tests were performed in the $0^{\circ}, 45^{\circ}$ and $90^{\circ}$ directions, while for AA6063-T6 the orientations of the tests were $0^{\circ}, 22.5^{\circ}$ and $45^{\circ}$ with respect to the ED. The results are presented in Fig. 3 (right) and Fig. 4 (right) for the two alloys. The figures show curves of the nominal stress $s=F / A_{0}$ versus the elongation $\Delta L_{g}$, where $F$ is the applied force, $A_{0}$ is the initial area of the minimum loadcarrying cross section within the shear-zone, and $\Delta L_{g}$ is the elongation of the extensometer gauge. The parallel tests

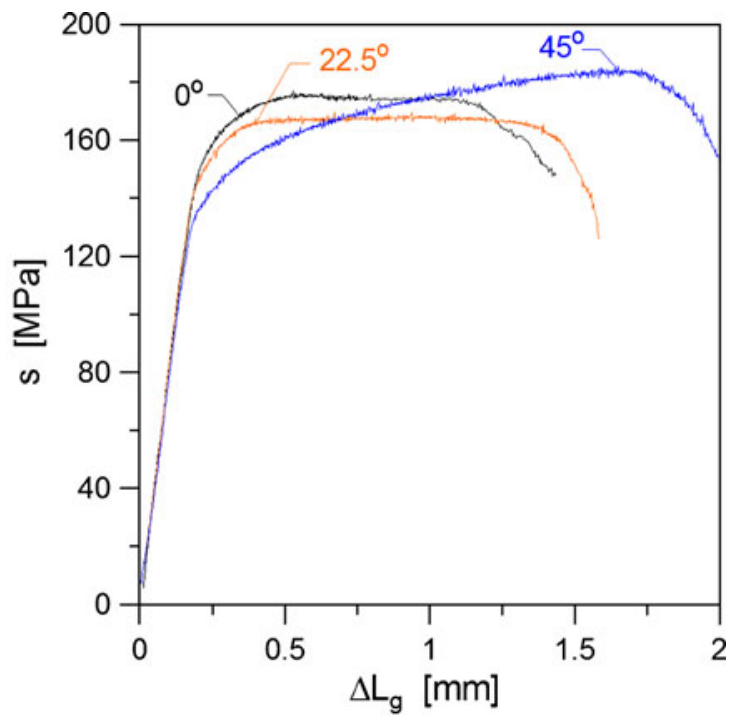

Fig. 4 Nominal stress versus elongation of extensometer gauge in plane-strain tension tests (left) and shear tests (right) of AA6063-T6 
showed insignificant scatter, and a representative test from each orientation is presented. Also in this loading mode, a strongly anisotropic response is observed. The AA7003-T6 material demonstrates the highest strength in tests machined from the $45^{\circ}$ direction. Note that the tests taken from the $0^{\circ}$ and $90^{\circ}$ directions yield at the same level, but the forceelongation curves deviate for large deformation. For AA6063-T6 the $0^{\circ}$ direction shows the highest yield strength followed by the $22.5^{\circ}$ and $45^{\circ}$ directions.

The ultimate force in these tests corresponds either to severely localized plastic deformation or, for some combinations of material and specimen orientation, to material fracture. The elongation at ultimate force is also seen to depend markedly upon orientation. For both materials, we observe that high yield strength is correlated with low elongation at ultimate force. In particular, the directions showing the lowest yield strength also show the highest specimen elongation. These observations are discussed in more detail in conjunction with the $\mathrm{FE}$ analyses in "Discussion".

\section{Constitutive model}

\section{Constitutive model}

The ingredients of the constitutive model are the anisotropic yield criterion, the associated flow rule and the nonlinear isotropic work-hardening rule. The constitutive model applied in this study is similar to that presented by Lademo et al. [12], but the anisotropic yield criterion is different. Thus, only a brief summary is given here, focusing on the yield function. The model is formulated for small elastic strains while plastic strains and rotations may be finite. To fulfil the principle of material frame indifference, a corotational stress formulation is adopted (e.g. [33]). Orthotropic anisotropy is assumed for the extruded aluminium profiles and thus there exist three mutually orthogonal planes of symmetry at each material point. The intersections of these planes are called the axes of orthotropy (or the principal axes of anisotropy), and these axes are chosen as the reference axes. In extruded aluminium profiles, the axes of orthotropy are the extrusion direction (ED), the transverse direction (TD) and the normal direction (ND) of the profiles, here chosen as $x$-axis, $y$-axis and $z$-axis, respectively.

The yield function $f$, which defines the elastic domain in stress space, is expressed in the form

$f(\boldsymbol{\sigma}, R)=\bar{f}(\boldsymbol{\sigma})-\left(Y_{0}+R\right) \leq 0$

where $Y_{0}$ is the reference yield stress and $R$ is the isotropic work-hardening variable. In Eq. $1, \bar{\sigma}=\bar{f}(\boldsymbol{\sigma})$ is the effective stress and $\sigma_{Y}=Y_{0}+R$ is the flow stress, representing the strength of the material.
Achani et al. [25] evaluated yield criteria for the two alloys based on uniaxial tensile tests data from seven in-plane directions and disc compression tests in the ND of the profile. The yield function Yld2004-18p of Barlat et al. [24] was selected, since it was found to give an accurate representation of the test data. This yield function is defined by

$\bar{f}(\boldsymbol{\sigma})=\sqrt[a]{\frac{1}{4} \phi}$

where

$$
\begin{aligned}
\phi= & \left|S^{\prime}{ }_{1}-S^{\prime \prime}{ }_{1}\right|^{a}+\left|S_{{ }_{1}}-S^{\prime \prime}{ }_{2}\right|^{a}+\left|S_{{ }^{\prime}}-{S^{\prime \prime}}_{3}\right|^{a}+\left|S^{\prime}{ }_{2}-S^{\prime \prime}{ }_{1}\right|^{a} \\
& +\left|S^{\prime}{ }_{2}-S^{\prime \prime}{ }_{2}\right|^{a}+\left|S^{\prime}{ }_{2}-S^{\prime \prime}{ }_{3}\right|^{a}+\left|S^{\prime}{ }_{3}-S^{\prime \prime}{ }_{1}\right|^{a}+\left|S^{\prime}{ }_{3}-S^{\prime \prime}{ }_{2}\right|^{a} \\
& +\left|S_{3}^{\prime}-S^{\prime \prime}{ }_{3}\right|^{a}
\end{aligned}
$$

The exponent $a$ is set to 8 for the aluminium alloys. In Eq. 3, $S_{i}^{\prime}$ and $S^{\prime \prime}{ }_{j}(i, j=1,2,3)$ are the principal values of two linear transformations of the stress tensor: $\mathbf{s}^{\prime}=\mathbf{C}^{\prime}$ : $\mathbf{s}=\mathbf{C}^{\prime}: \mathbf{T}: \boldsymbol{\sigma}$ and $\mathbf{s}^{\prime \prime}=\mathbf{C}^{\prime \prime}: \mathbf{s}=\mathbf{C}^{\prime \prime}: \mathbf{T}: \boldsymbol{\sigma}$, where $\mathbf{s}=\mathbf{T}:$ $\boldsymbol{\sigma}$ is the stress deviator. The fourth-order tensors $\mathbf{C}^{\prime}$ and $\mathbf{C}^{\prime \prime}$ contain the anisotropy constants, and in Voigt notation they are expressed as

$$
\begin{aligned}
\mathbf{C}^{\prime} & =\left[\begin{array}{cccccc}
0 & -c^{\prime}{ }_{12} & -c^{\prime}{ }_{13} & 0 & 0 & 0 \\
-c^{\prime}{ }_{21} & 0 & -c^{\prime}{ }_{23} & 0 & 0 & 0 \\
-c^{\prime}{ }_{31} & -c^{\prime}{ }_{32} & 0 & 0 & 0 & 0 \\
0 & 0 & 0 & c^{\prime}{ }_{44} & 0 & 0 \\
0 & 0 & 0 & 0 & c^{\prime}{ }_{55} & 0 \\
0 & 0 & 0 & 0 & 0 & c^{\prime}{ }_{66}
\end{array}\right], \\
\mathbf{C}^{\prime \prime} & =\left[\begin{array}{cccccc}
0 & -c^{\prime \prime}{ }_{12} & -c^{\prime \prime}{ }_{13} & 0 & 0 & 0 \\
-c^{\prime \prime}{ }_{21} & 0 & -c^{\prime \prime}{ }_{23} & 0 & 0 & 0 \\
-c^{\prime \prime}{ }_{31} & -c^{\prime \prime}{ }_{32} & 0 & 0 & 0 & 0 \\
0 & 0 & 0 & c^{\prime \prime}{ }_{44} & 0 & 0 \\
0 & 0 & 0 & 0 & c^{\prime \prime}{ }_{55} & 0 \\
0 & 0 & 0 & 0 & 0 & c^{\prime \prime}{ }_{66}
\end{array}\right]
\end{aligned}
$$

The two linear transformations provide 18 coefficients that can be used to describe the plastic anisotropy of the material. The yield function reduces to Hershey's isotropic yield function [34] when all coefficients are equal to one. The reader is referred to Barlat et al. [24] for more details about the Yld2004-18p criterion.

An often assumed nonlinear isotropic work-hardening rule reads as (e.g. [35])

$R(\bar{\varepsilon})=\sum_{i=1}^{2} Q_{R i}\left(1-\exp \left(-C_{R i} \bar{\varepsilon}\right)\right)$

where $\bar{\varepsilon}$ is the accumulated plastic strain and $Q_{R i}$ and $C_{R i}$ are isotropic work-hardening constants. The rate form of the isotropic work-hardening rule is

$\dot{R}=H_{R}(\bar{\varepsilon}) \dot{\bar{\varepsilon}}$ 
where the work-hardening modulus is defined as

$H_{R}(\bar{\varepsilon})=\sum_{i=1}^{2} C_{R i} Q_{R i} \exp \left(-C_{R i} \bar{\varepsilon}\right)$

It is seen from Eq. 5 that the work-hardening saturates, since $R \rightarrow \sum Q_{R i}$ when $\bar{\varepsilon} \rightarrow \infty$. This is not always confirmed by experiments, where nearly linear workhardening is often exhibited at large strains. To account for this, the work-hardening rule applied in this study is defined by

$\dot{R}=\left\{\begin{array}{lll}H_{R}(\bar{\varepsilon}) \dot{\bar{\varepsilon}} & \text { for } \quad H_{R}(\bar{\varepsilon}) \geq H_{R, \text { min }} \\ H_{R, \text { min }} \dot{\bar{\varepsilon}} & \text { for } \quad H_{R}(\bar{\varepsilon})<H_{R, \text { min }}\end{array}\right.$

where $H_{R}$ is defined by Eq. 7 and $H_{R, \min }$ is the minimum work-hardening rate reached at large strains. The initial value $R(0)=0$ is assumed herein. It follows that Eqs. 5 and 6 are only valid until an accumulated plastic strain $\bar{\varepsilon}^{*}$ implicitly defined by

$H_{R, \min }=H_{R}\left(\bar{\varepsilon}^{*}\right)=\sum_{i=1}^{2} C_{R i} Q_{R i} \exp \left(-C_{R i} \bar{\varepsilon}^{*}\right)$

The adopted work-hardening rule is a simple extension of the Voce rule, using two exponential terms instead of one and with the possibility of a constant work-hardening rate at large plastic strains.

The constitutive model has been implemented as a userdefined material model in LS-DYNA [36] for use with shell and brick elements. In this study, brick elements are used in all simulations.

Parameters and analytical model predictions

Achani et al. [25] used 15 measured dimensionless quantities to determine the parameters of the yield function: the flow stress ratios $r_{\alpha}$ and the strain ratios $R_{\alpha}$ from uniaxial tension tests in seven in-plane directions $\alpha$ and the equibiaxial strain ratio $R_{b}$ from a disc compression test in the ND of the flat profile. The flow stress ratio $r_{\alpha}$ was defined as

$r_{\alpha}=\left.\frac{\sigma_{\alpha}}{\sigma_{0}}\right|_{W^{p}}$

where $\sigma_{\alpha}$ is the flow stress in the $\alpha$ direction and $\sigma_{0}$ is the flow stress in the $\operatorname{ED}\left(\alpha=0^{\circ}\right)$ at given specific plastic work $W^{p}$. An average value of $r_{\alpha}$ defined for plastic strains up to incipient necking was then used in the calibration of the yield criterion. The strain ratio for the $\alpha$ direction was calculated as

$R_{\alpha}=\frac{\varepsilon_{W}^{p}}{\varepsilon_{T}^{p}}=\frac{\ln \left(w / w_{0}\right)}{\ln \left(t / t_{0}\right)}$ where $\varepsilon_{W}^{p}$ and $\varepsilon_{T}^{p}$ are the plastic strains in width and thickness direction of the tensile specimen, $w_{0}$ and $t_{0}$ are the width and thickness of the gauge area before testing, while $w$ and $t$ are the same values after testing (measured on the unloaded specimen). In the disc compression tests, the diameters both parallel and perpendicular to the ED as well as the thickness of the disc were measured prior to and after the deformation. The measured dimensions were then used to calculate the logarithmic plastic strains $\varepsilon_{x}^{p}, \varepsilon_{y}^{p}$ and $\varepsilon_{z}^{p}$ in $\mathrm{ED}, \mathrm{TD}$ and ND, respectively. The equibiaxial strain ratio $R_{b}$ was then defined as [20]

$R_{b}=\frac{\varepsilon_{y}^{p}}{\varepsilon_{x}^{p}}$

The parameters of the yield function were found by minimizing a sum of squared residuals that measures the error in the calculated dimensionless quantities compared to the experimental ones. There is no unique way of defining such a sum of squared residuals, since different weight has to be put on the various dimensionless quantities to obtain equally good representation of the anisotropy in strength and plastic flow. Achani et al. [25] defined the sum of squared residuals $S$ as

$$
\begin{aligned}
& S=\sum_{\alpha}\left(r_{\alpha}^{\exp }-r_{\alpha}^{\mathrm{mod}}\right)^{2}+\left(1-r_{b}^{\mathrm{mod}}\right)^{2} \\
& +\sum_{\alpha} w\left(\left(R_{\alpha}^{\exp }\right)^{\frac{1}{a-1}}-\left(R_{\alpha}^{\bmod }\right)^{\frac{1}{a-1}}\right)^{2}+w\left(\left(R_{b}^{\exp }\right)^{\frac{1}{a-1}}-\left(R_{b}^{\bmod }\right)^{\frac{1}{a-1}}\right)^{2}
\end{aligned}
$$

where $w$ is a weight applied to the strain ratios and $r_{b}$ is the ratio between the yield stress in equibiaxial tension and the yield stress in uniaxial tension in the ED. Owing to lack of experimental data $r_{b}$ was assumed equal to unity. The parameters of the yield function were then obtained by minimizing the sum of squared residuals $S$, by using the solver function of Microsoft Excel. Since these experiments provide no information about the out-of-plane yield stresses in tension and shear, these quantities were set equal to their isotropic values, as proposed by Barlat et al. [24].

Fig. 5 presents experimental and fitted values of the flow stress ratio $r_{\alpha}$ and the strain ratio $R_{\alpha}$ with respect to angle of tension for AA7003-T6. Fits with $w$ equal to 1, 0.5 and 0.2 are included. Fig. 6 presents similar plots for AA6063T6. Yld2004-18p gives an almost perfect fit for the recrystallized alloy AA6063-T6 independently of the weight $w$, while the results for the fibrous, non-recrystallized alloy AA7003-T6 are slightly less accurate. Figs. 7 and 8 present contour plots of the yield surfaces obtained by Yld2004-18p using $w$ equal 0.5 for AA7003-T6 and AA6063-T6, respectively, as represented in the space of the stress components $\sigma_{x}, \sigma_{y}$ and $\sigma_{x y}$ The figures clearly demonstrate the influence of the different textures of the two alloys on the shape of the yield surface. 
Fig. 5 Comparison of predicted and experimental flow stress ratios (left) and strain ratios (right) as function of direction of uniaxial tension for AA7003-T6 using Yld2004-18p (from Achani et al. [25])

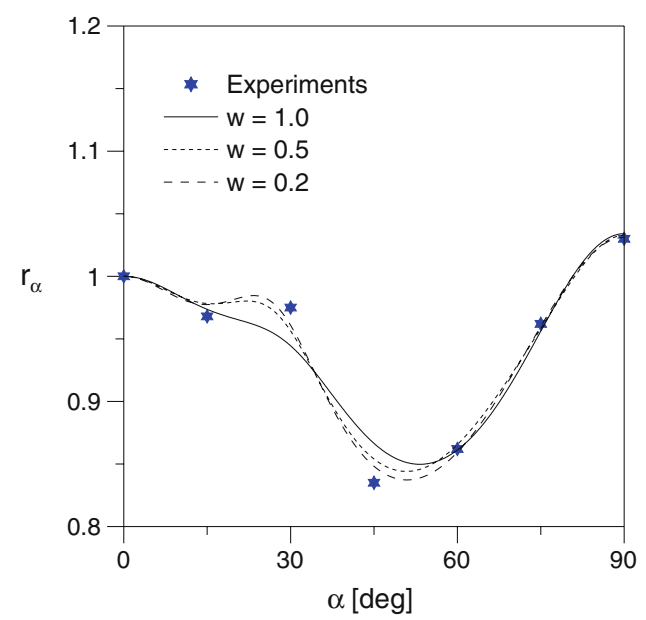

Valuable information on the predictive quality of the yield function for loading in plane-strain tension and shear is obtained by defining two additional stress ratios

$r_{\alpha}^{p s t}=\frac{\sigma_{\alpha}}{\sigma_{0}}, \quad r_{\alpha}^{s}=\frac{\sigma_{\alpha \beta}}{\sigma_{0}}$

where $\sigma_{\alpha}$ is the major normal stress in plane-strain tension in the $\alpha$ direction, $\sigma_{\alpha \beta}$ is the shear stress for the specimen oriented in the $\alpha$ direction, and $\sigma_{0}$ is the stress in uniaxial tension in the ED. All stresses are taken at incipient yielding. The stress states in the plane-strain tension and shear tests are transformed from the specimen frame to the principal axes of anisotropy by

$\left\{\begin{array}{c}\sigma_{x} \\ \sigma_{y} \\ \sigma_{x y}\end{array}\right\}=\left[\begin{array}{ccc}\cos ^{2} \alpha & \sin ^{2} \alpha & -2 \sin \alpha \cos \alpha \\ \sin ^{2} \alpha & \cos ^{2} \alpha & 2 \sin \alpha \cos \alpha \\ \sin \alpha \cos \alpha & -\sin \alpha \cos \alpha & \cos ^{2} \alpha-\sin ^{2} \alpha\end{array}\right]\left\{\begin{array}{c}\sigma_{\alpha} \\ \sigma_{\beta} \\ \sigma_{\alpha \beta}\end{array}\right\}$

where $\sigma_{\alpha}, \sigma_{\beta}$ and $\sigma_{\alpha \beta}$ are the stress components in the specimen frame for a specimen oriented in the direction $\alpha$ with respect to the ED. For the plane-strain tension test in the $\alpha$ direction it is assumed that the minor normal stress is given by $\sigma_{\beta}=v \sigma_{\alpha}$ at incipient yielding where $v$ is Poisson's ratio. The shear stress at yielding is assumed to be zero. For the shear test in the $\alpha$ direction the only nonzero stress component is assumed to be the shear stress $\sigma_{\alpha \beta}$. Using the yield function, Eq. 1, we obtain the variation of the stress ratios with the orientation $\alpha$ of the test specimen as

$$
\begin{aligned}
r_{\alpha}^{p s t} & =\frac{1}{\bar{f}\left(\cos ^{2} \alpha+v \sin ^{2} \alpha, \sin ^{2} \alpha+v \cos ^{2} \alpha, 0,0,0,(1-v) \sin \alpha \cos \alpha\right)} \\
r_{\alpha}^{s} & =\frac{1}{\bar{f}\left(-2 \sin \alpha \cos \alpha, 2 \sin \alpha \cos \alpha, 0,0,0, \cos ^{2} \alpha-\sin ^{2} \alpha\right)}
\end{aligned}
$$

where the Voigt notation is used and thus $\bar{f}(\boldsymbol{\sigma})=$ $\bar{f}\left(\sigma_{x}, \sigma_{y}, \sigma_{z}, \sigma_{z x}, \sigma_{z y}, \sigma_{x y}\right)$. Note that the analytical calculations assume idealized and homogeneous stress states and are only valid at incipient yielding. The actual tests do not necessarily produce these conditions. The calculated
Fig. 6 Comparison of predicted and experimental flow stress ratios (left) and strain ratios (right) as function of direction of uniaxial tension for AA6063-T6 using Yld2004-18p (from Achani et al. [25])
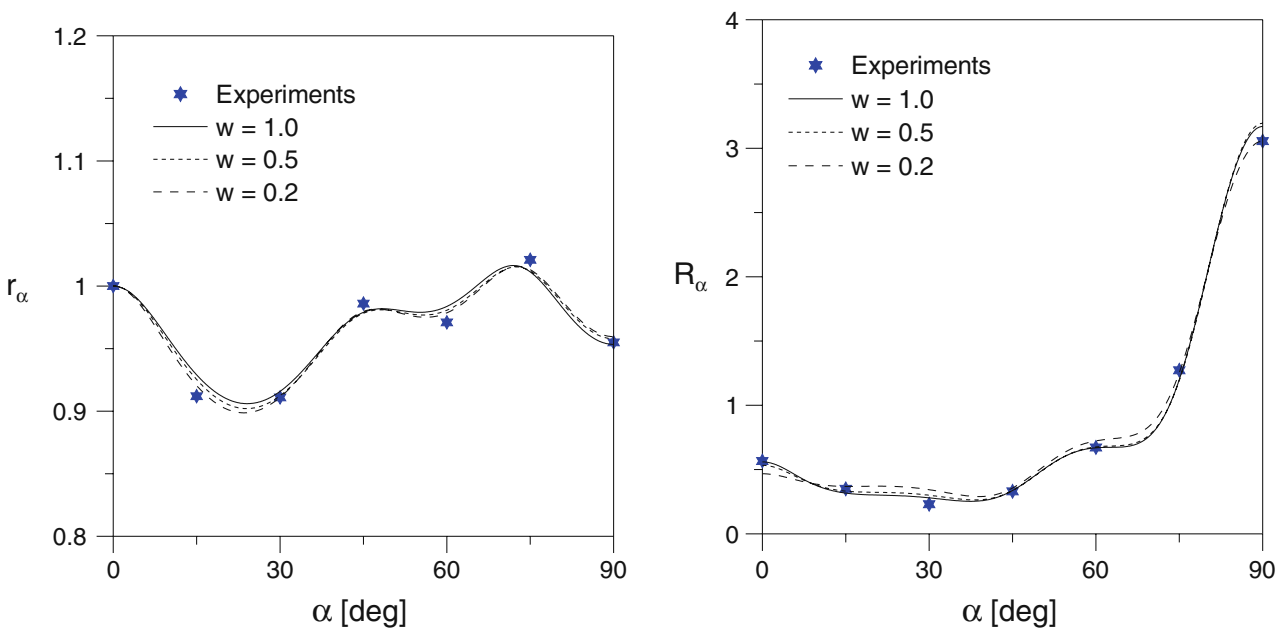
Fig. 7 Yield surface for AA7003-T6: Yld2004-18p with weight $w=0.5$ (from Achani et al. [25])

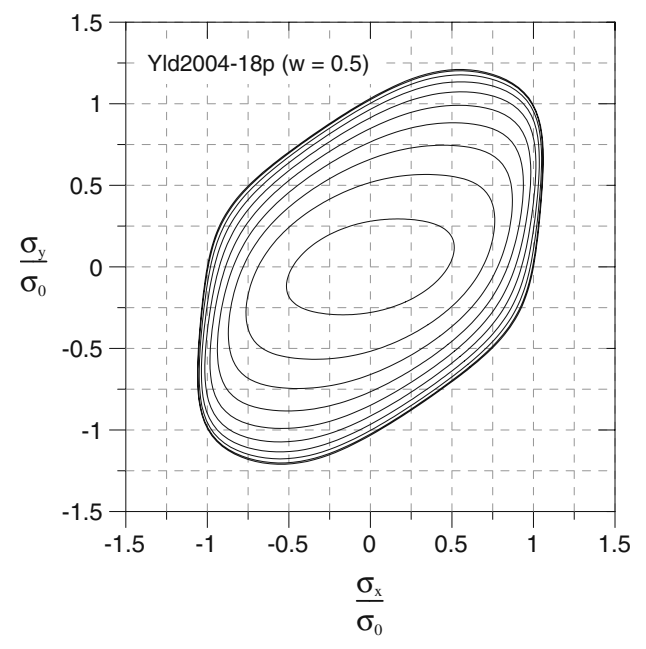

stress ratios $r_{\alpha}^{p s t}$ and $r_{\alpha}^{s}$ are provided in Figs. 9 and 10 for the AA7003-T6 and AA6063-T6 materials, respectively.

For plane-strain tension the calibrated yield criterion predicts the highest strength in the $90^{\circ}$ direction for both materials, which is in accordance with the experimental results. For the AA7003-T6 material and $w$ equal to 0.5 and 0.2 , the yield criterion predicts somewhat lower strength in the $45^{\circ}$ direction than for the $0^{\circ}$ direction. In the experiments, the opposite trend is observed. For the AA6063-T6 material the yield criterion predicts about the same strength for the $0^{\circ}$ and $45^{\circ}$ directions, while the experiments demonstrate higher strength in the $45^{\circ}$ direction than in the $0^{\circ}$ direction.

Shear tests oriented in the $0^{\circ}$ and $90^{\circ}$ directions should theoretically produce identical results for small strains. Indeed, the experimental tests done in these directions, i.e. for the AA7003-T6 material, result in identical yield strengths. Note, however, that the experimental curves for these tests separate after some deformation, i.e. the test in the $90^{\circ}$ direction seems to work-harden more than the test in the $0^{\circ}$ direction. There are two possible explanations for this observation. (a) The shear test specimen may produce stress states somewhere in between pure and simple shear, causing secondary stress components that would have different orientation for the two tests. (b) The other explanation is related to different texture evolution for the two orientations of the specimen. These issues are discussed in more detail below based on non-linear FE analyses and polycrystal plasticity calculations. We further see that the model represents much higher shear strength in the $45^{\circ}$ direction as compared to the other directions. This is also in accordance with the experimental results, as presented in Fig. 3. For the AA6063-T6 material the shear tests display highest yield strength in the $0^{\circ}$ direction followed by the $22.5^{\circ}$ and $45^{\circ}$ directions. The predictions obtained with the calibrated yield criterion are in good accordance with these experimental results.
Fig. 8 Yield surface for AA6063-T6: Yld2004-18p with weight $w=0.5$ (from Achani et al. [25])
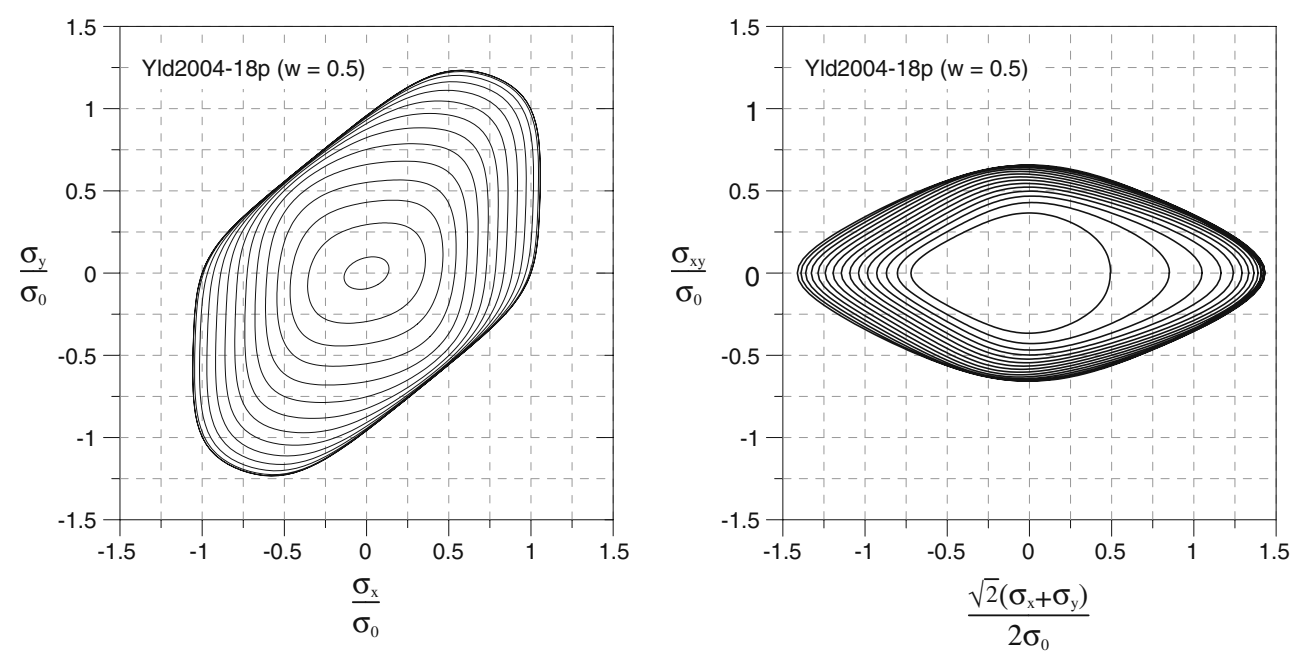
Fig. 9 Predicted stress ratios in plane-strain tension (left) and shear (right) for AA7003-T6 based on Yld2004-18p and weights $w=0.2,0.5,1.0$

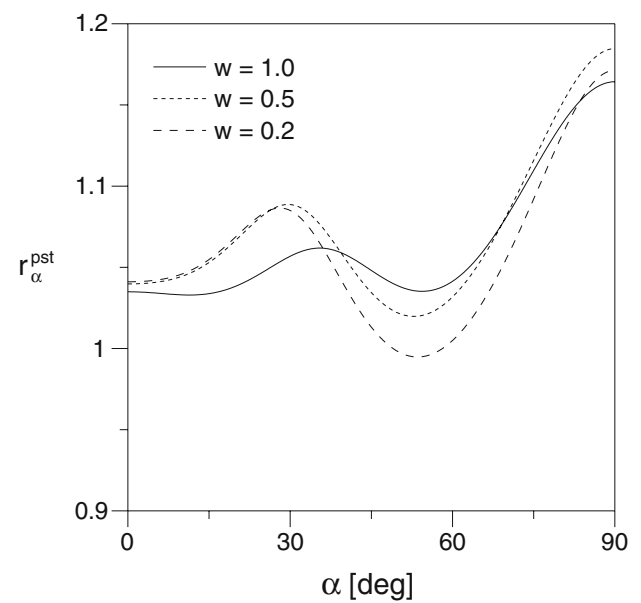

\section{Finite element simulations}

Modelling and simulation procedures

To enable a proper evaluation of the constitutive model, non-linear Finite Element analyses were performed using the explicit solver of the general-purpose program LSDYNA. The FE models of the plane-strain tension and shear test specimens are shown in Figs. 11 and 12, respectively. Eight node hexahedrons with reduced integration and stiffness-based hourglass control were used to discretize the specimens.

The plane-strain tension specimen was modelled with 18,120 elements in the deformable central part, giving a characteristic element size of $0.8 \times 0.8 \times 0.4 \mathrm{~mm}^{3}$. The smallest dimension was in the ND, and as a result there were five elements through the thickness of the specimen. With reference to Fig. 11, the lower rigid part of the specimen was fixed, while a velocity-time history with smooth ramp-up was prescribed for the upper rigid part. An explicit solver requires small time steps for numerical stability reasons. To keep the number of time steps within a reasonable value, the simulation time was set to $3 \mathrm{~ms}$.

The shear specimen was discretized using 43,335 solid elements, out of which two thirds were located in the vicinity of the shear zone of the specimen. The characteristic element size in the shear zone was $0.1 \times 0.1 \times 0.2 \mathrm{~mm}^{3}$. Here the largest dimension was in the $\mathrm{ND}$, giving 10 elements through the thickness of the specimen. With reference to Fig. 12 , the lower rigid bolt was fixed, while a velocity-time history with smooth ramp-up was prescribed for the upper rigid bolt. The simulation time was $10 \mathrm{~ms}$.

Since the simulation times are several orders of magnitude smaller than the duration of the experiments, it was carefully checked that the kinetic energy of the specimen was always a small fraction of the internal energy, so that the simulations could be considered to be quasi-static.

The present study does not aim at describing the postlocalization response of the test specimens. In particular, the FE model of the plane-strain tension test is rather coarse and may not provide a converged solution in the post-
Fig. 10 Predicted stress ratios in plane-strain tension (left) and shear (right) for AA6063-T6 based on Yld2004-18p and weights $w=0.2,0.5,1.0$
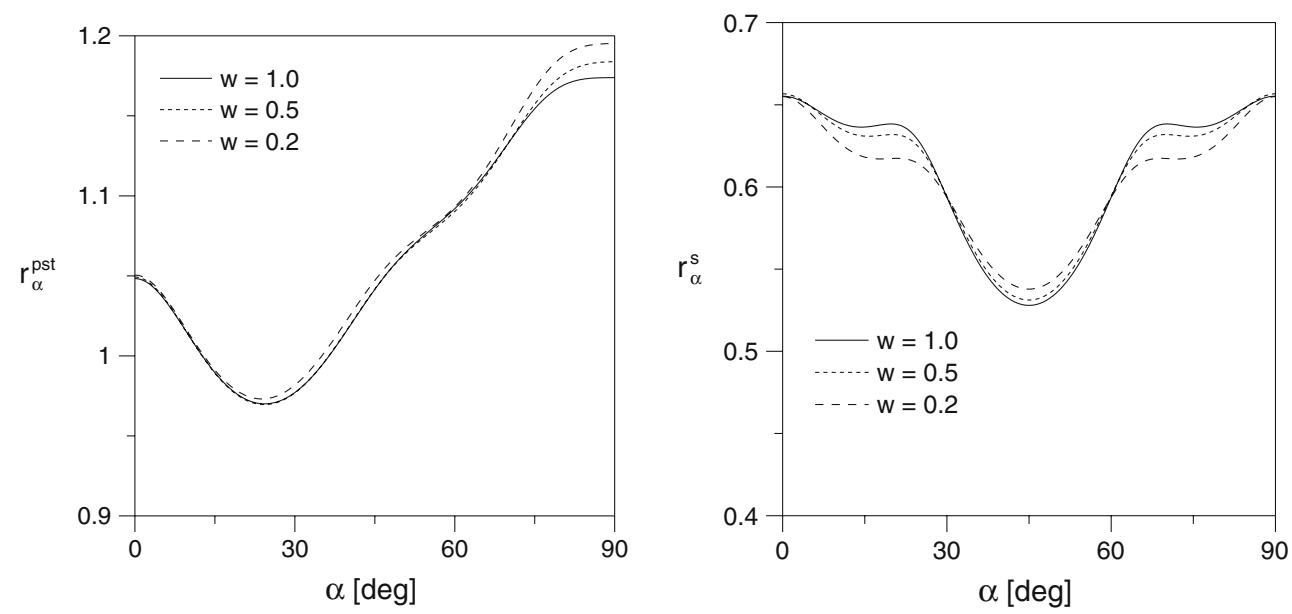
Fig. 11 Finite element mesh of the plane-strain tension specimen (left) and enlarged view of gauge section (right)

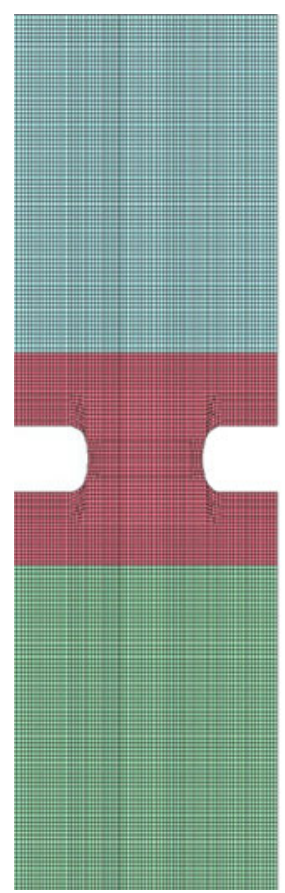

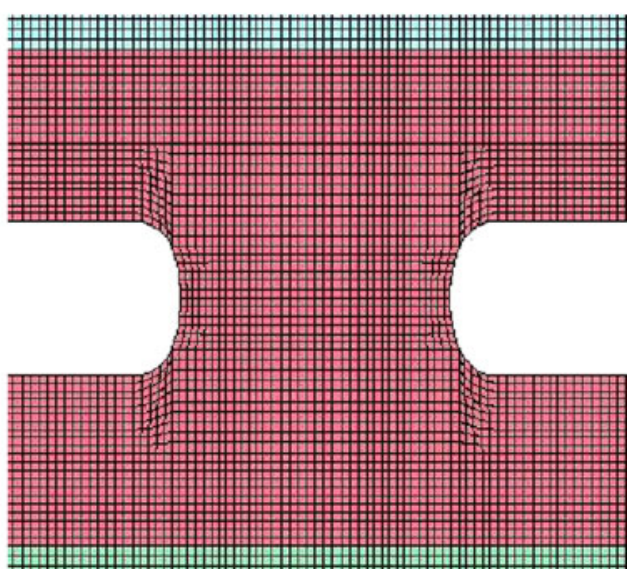

necking region. The FE mesh of the shear test specimen is neither guaranteed to represent all possible localization modes. Despite the dense mesh, the strain localization might occur in bands narrower than the characteristic length scale of the mesh. To conclude on these issues, measurements of the strain field within the shear zone of the specimen are required. Such field measurements were not performed for the actual test series.
Results and comparison with experiments

Figs. 13 and 14 show the experimental and predicted nominal stress versus elongation for the AA7003-T6 and AA6063-T6 materials, respectively. We note that the qualitative trends revealed by the stress ratios $r_{\alpha}^{p s t}$ and $r_{\alpha}^{s}$ for plane-strain tension and shear, respectively, correlate well with the strength anisotropy predicted by the FE
Fig. 12 FE mesh of shear specimen (left), including enlarged view of shear zone (right)
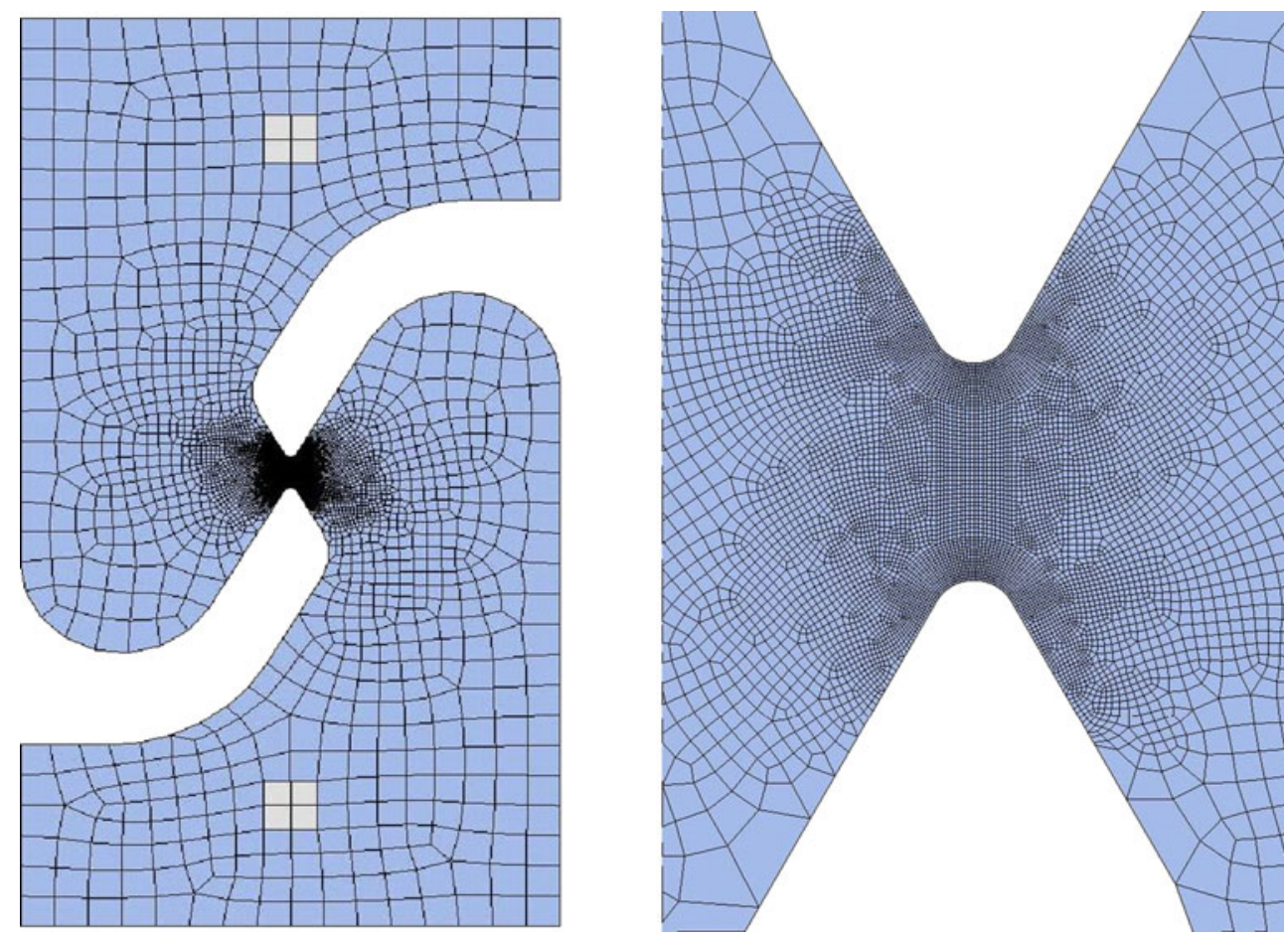

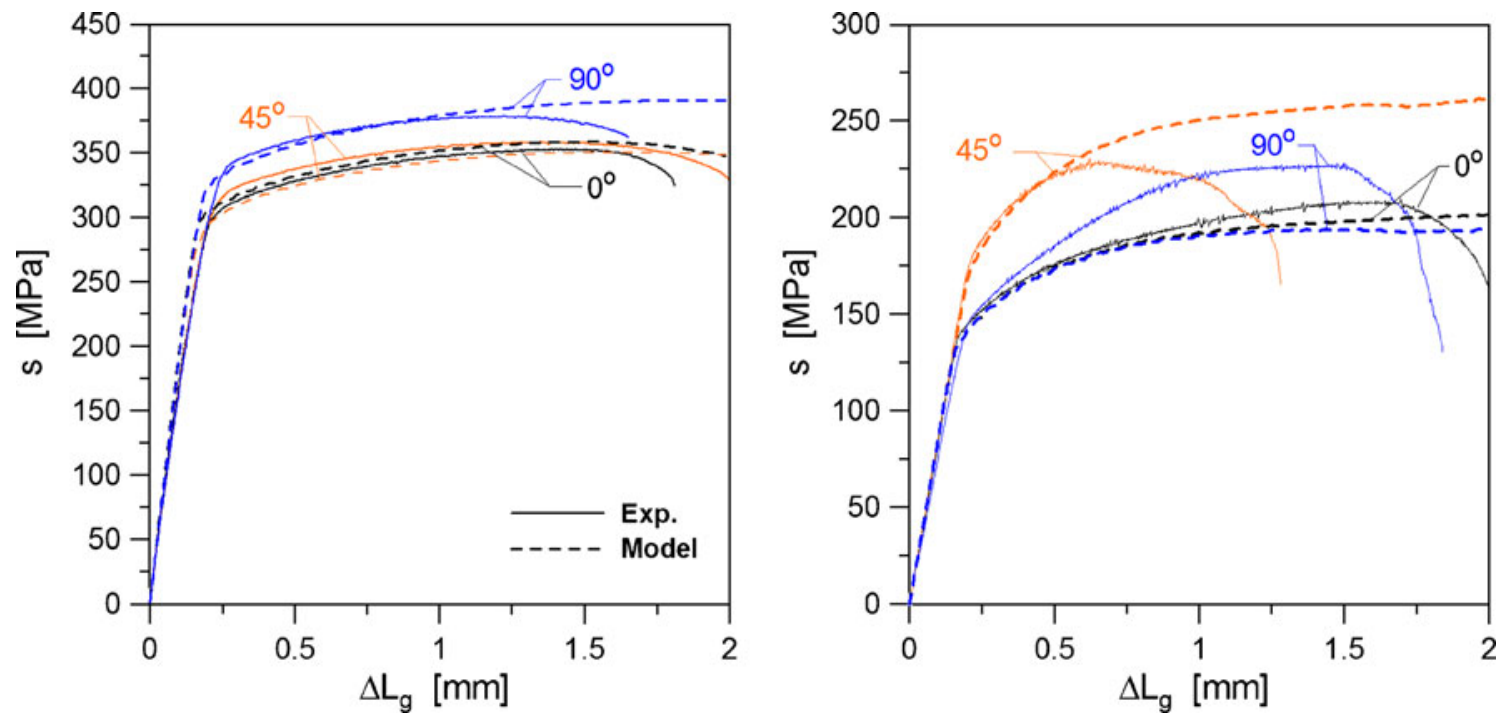

Fig. 13 Nominal stress versus elongation of extensometer gauge in plane-strain tension tests (left) and shear tests (right) of AA7003-T6

simulations. This means that the plane-strain tension and shear tests could have been used to improve the parameter identification, e.g. with respect to the value of the weight $w$ for the AA7003-T6 materials, prior to the execution of the FE simulations. For instance, for plane-strain tension, Fig. 9 (left) demonstrates that the choice $w=0.5$ represents a lower strength in the $45^{\circ}$ direction than in the $0^{\circ}$ direction, while the opposite is observed in the experiments. Similarly, for the AA6063-T6 material, Fig. 10 (left) shows that the model represents the same strength in $0^{\circ}$ and $45^{\circ}$ directions, while the experimental data show that the strength in the $45^{\circ}$ direction is significantly higher. A slight modification of the parameters would facilitate a qualitatively correct representation. In particular, it is suggested that the stress ratios $r_{\alpha}^{p s t}$ and $r_{\alpha}^{s}$ could be used to pin-point critical test directions in plane-strain tension and shear based on the uniaxial tension test. In this way, the test programme in plane-strain tension and shear could be planned to provide the best possible support for the parameter identification and/or the evaluation of the yield criterion. For instance, from Fig. 9 (left) we conclude that plane-strain tension tests in the directions $\sim 30^{\circ}$ and $\sim 48^{\circ}$ could possibly provide information about extremal points in the directional yield strength in plane-strain tension.

The ultimate force in the plane-strain tension test corresponds to the onset of necking. For both materials it is seen that the assumption of isotropic work-hardening is unable to capture the lower elongation at necking in the $90^{\circ}$ direction. It was found by Achani [31] that also in uniaxial
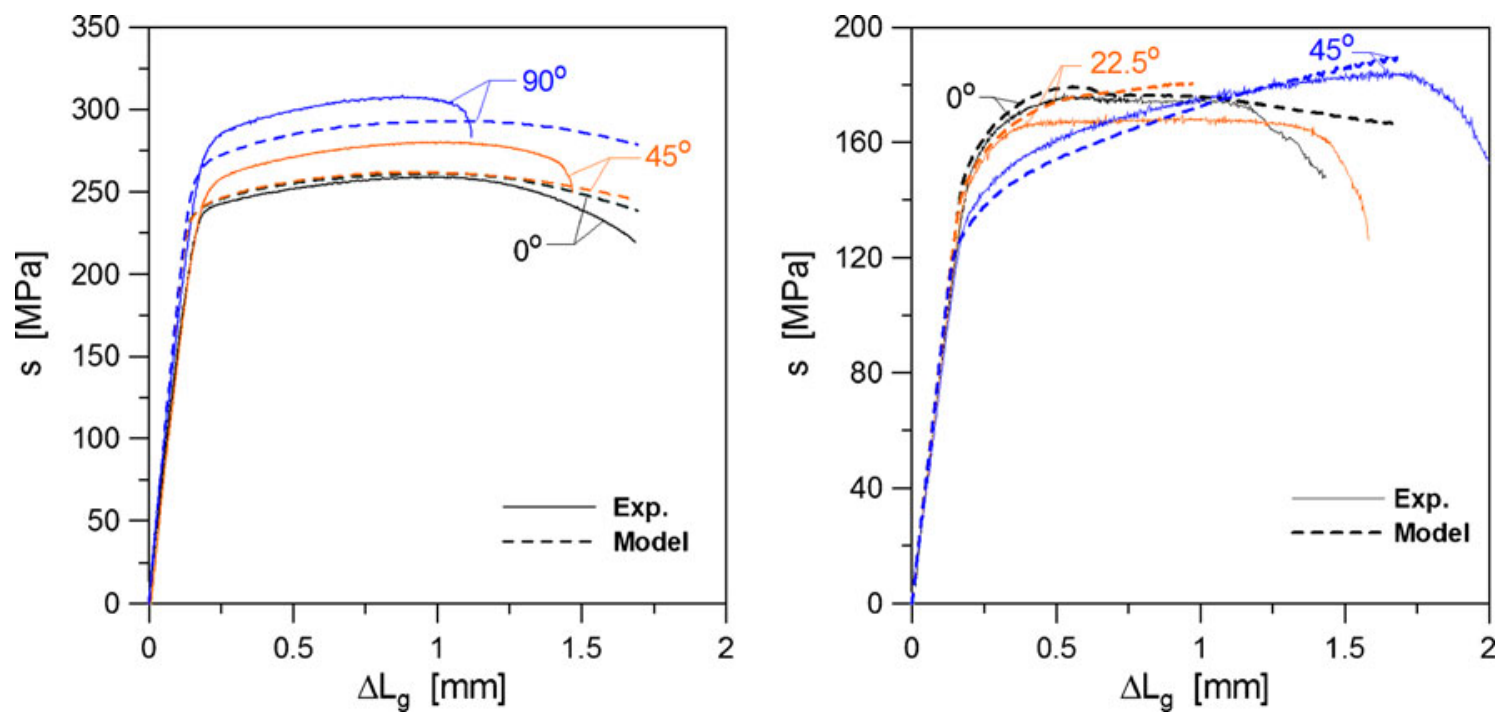

Fig. 14 Nominal stress versus elongation of extensometer gauge in plane-strain tension tests (left) and shear tests (right) of AA6063-T6 
tension the isotropic work-hardening rule was not capable of properly representing the variation in elongation at necking with varying tensile direction.

For the shear tests of the AA7003-T6 material the yield strength prediction is correct, but the model is unable to predict the more rapid work-hardening in the $90^{\circ}$ direction compared to the $0^{\circ}$ direction. Furthermore, the predicted work-hardening in these directions is too low. The predicted response for the $45^{\circ}$ direction deviates from the experimental one for $\Delta L_{g}$ greater than approximately $0.5 \mathrm{~mm}$. It is believed that the ultimate force of this test is governed by the formation of a localized shear band within the central gauge section that is not aligned with the specimen orientation. This localization is not predicted by the FE model. For the AA6063-T6 material the directional variation of the yield strength is captured with reasonable accuracy. The model properly represents the highly different responses of the $0^{\circ}$ and $45^{\circ}$ tests. For the high-strength $0^{\circ}$ direction a localized shear band was formed for $\Delta L_{g}$ greater than approximately $0.5 \mathrm{~mm}$, which corresponds to the ultimate force in the test. In the $45^{\circ}$ direction, exhibiting the lowest shear strength, the strain in the shear zone is less localized. The model does not capture the ultimate strength of the experiment in the $22.5^{\circ}$ direction.

\section{Discussion}

It has previously been demonstrated by Achani et al. [25] that the yield surface Yld2004-18p, in combination with the associated flow rule, is able to represent the highly complex directional variations of the flow stress ratios $r_{\alpha}$ and plastic strain ratios $R_{\alpha}$ exhibited in uniaxial tensile tests on the extruded aluminium alloys AA6063-T6 and AA7003-T6. Plane-strain tension and shear tests are considered to be suitable for assessing the accuracy of the anisotropic yield criterion and the isotropic work-hardening rule for stress states other than those realized in uniaxial tensile tests. It is suggested to select critical directions for plane-strain tension and shear testing from an evaluation of the stress ratios $r_{\alpha}^{p s t}$ and $r_{\alpha}^{s}$ that can be determined analytically as soon as the anisotropic yield criterion has been calibrated based on uniaxial tension tests in several material directions. The results from the planestrain tension and shear tests may then be used to determine an improved parameter set for the anisotropic yield criterion.

The specimen geometries adopted in the plane-strain tension and shear tests are simple to make from sheets, plates or flat profiles, but they do not provide ideal and homogeneous stress states, as assumed in the analytical calculation of the stress ratios $r_{\alpha}^{p s t}$ and $r_{\alpha}^{s}$. Non-linear FE analyses were therefore required to evaluate the calculated stress ratios in plane-strain tension and shear and to further interpret the experimental results. The qualitative trends revealed by the stress ratios $r_{\alpha}^{p s t}$ and $r_{\alpha}^{s}$ correlate well with the predicted directional variation of the yield strength in FE simulations of the plane-strain tension and shear tests. This result supports the use of plane-strain tension and shear tests and the analytical stress ratios $r_{\alpha}^{p s t}$ and $r_{\alpha}^{s}$ as a supplement to uniaxial tension tests in the parameter identification of the anisotropic yield criterion. The FE simulations are further used to confirm that the actual specimen geometries provide strain and stress states sufficiently close to the ideal plane strain and shear conditions.

The yield function with parameters identified from the uniaxial tensile test data offers a reasonably accurate representation of the yield strength anisotropy observed in plane-strain tension and shear. The largest deviations are seen for the plane-strain tension tests in the $45^{\circ}$ and $90^{\circ}$ directions for the AA6063-T6 material. As already proposed, the data from the plane-strain tension tests and/or the shear tests may be used to find new parameter sets giving an improved representation of all available experimental data. An example comparing the original calibration of the anisotropic yield criterion with a new calibration taking into account the additional experimental data from the planestrain tension tests is provided in Fig. 15. As seen, the new set of parameters gives higher values of the stress ratio $r_{\alpha}^{p s t}$ in the $45^{\circ}$ and $90^{\circ}$ directions, as suggested by these experiments, while maintaining nearly the same directional variations of the stress ratio $r_{\alpha}$ and plastic strain ratio $R_{\alpha}$ in uniaxial tension and the stress ratio $r_{\alpha}^{s}$ in shear. It thus seems that the Yld2004-18p yield function is sufficiently flexible for accurate representation of the plastic anisotropy exhibited by these highly textured aluminium alloys.

It has previously been shown by Achani [31] that the assumption of isotropic work-hardening is not in agreement with the directional dependency of the uniform elongation (or strain to diffuse necking) in uniaxial tension. In this study, we find that with isotropic work-hardening, the prediction of the directional variation of the elongation at necking in plane-strain tension is not reliable. In particular, non-conservative estimates of the elongation at necking in the $90^{\circ}$ direction are obtained for both materials. It is further seen that the FE model predicts comparable response in the shear tests in the $0^{\circ}$ and $90^{\circ}$ directions, which is not in accordance with the experiments. Since the secondary stress components occurring in the shear test should be accounted for in the FE model, this deviation might be attributed to significant texture evolution in the shear test already at moderate strain levels. Again this observation discredits the assumption of isotropic workhardening, since significant texture evolution would change the shape of the yield surface with plastic straining.

The influence of texture evolution in the shear test was investigated by conducting polycrystal plasticity calculations using the Visco-Plastic Self Consistent (VPSC) 
Fig. 15 Stress and plastic strain ratios obtained by the original and new calibrations of the anisotropic yield criterion for AA6063-T6
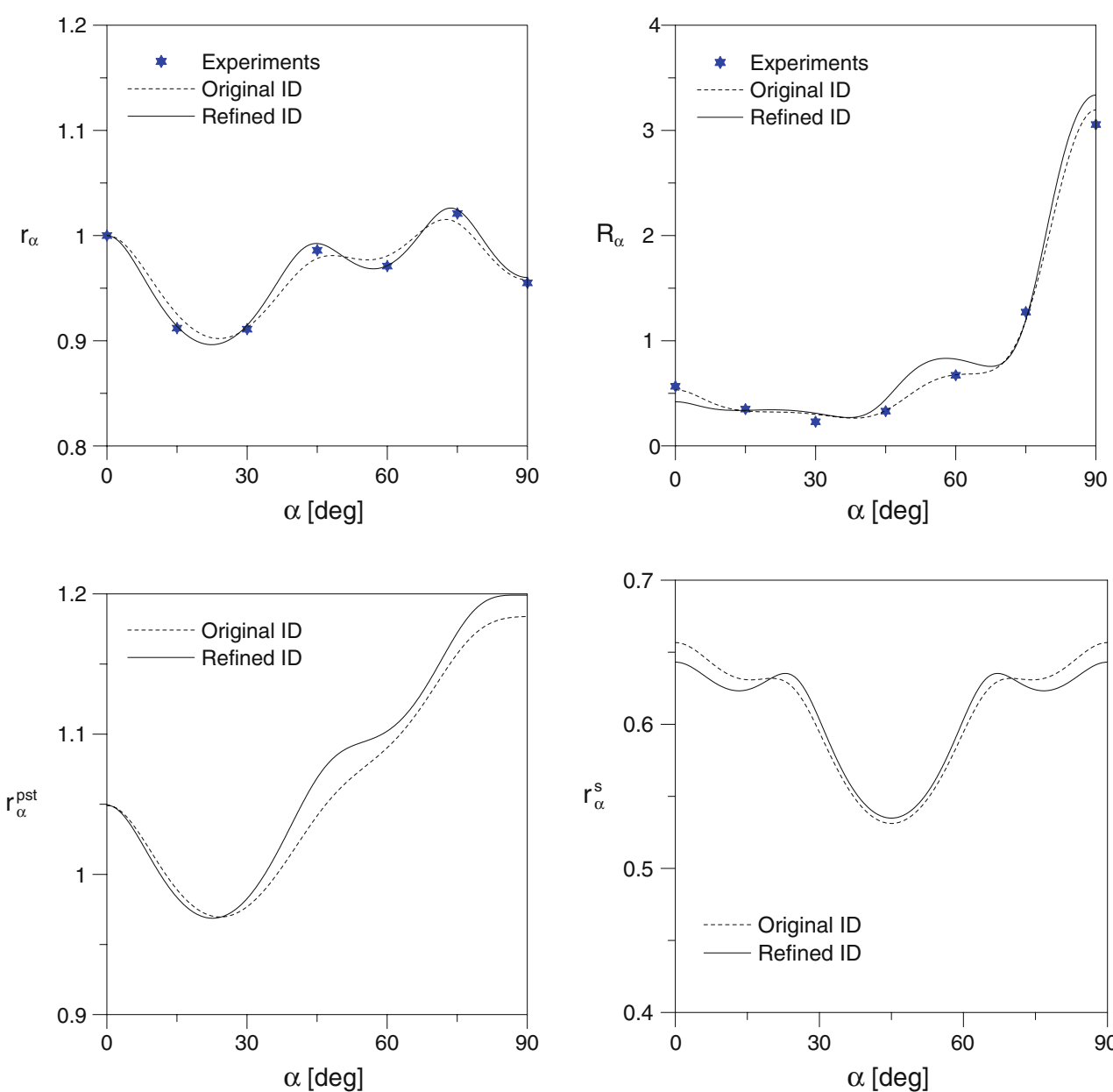

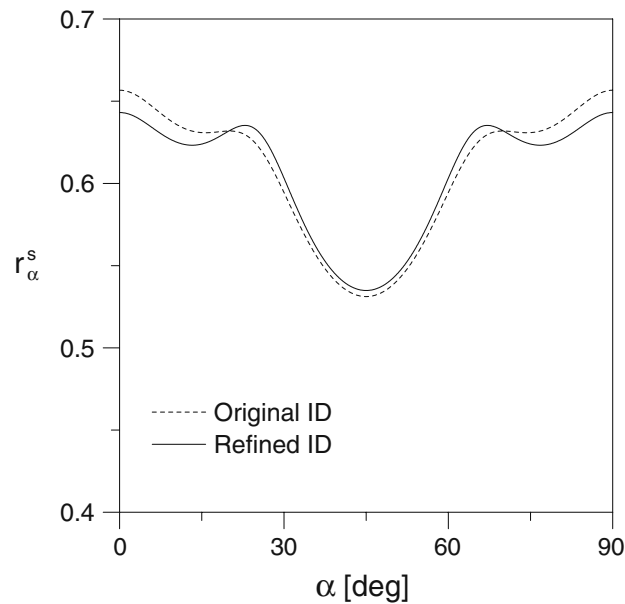

formulation developed by Lebensohn and Tomé [37]. The VPSC formulation is a very versatile polycrystal plasticity approach which accounts for anisotropic properties of both the individual crystals and the aggregate as a whole and, as such, allows tackling of non-isotropic work-hardening due to texture changes. In order to cut down computation time for the polycrystal-plasticity calculations, 1,000 individual orientations were taken at random from the full EBSD data sets (see Ref. [38]). Note that for a consideration of the full polycrystal properties orthotropic sample symmetry must not be applied, i.e. $0^{\circ} \leq \phi_{1} \leq 360^{\circ}$.

In VPSC polycrystal-plasticity simulations of forming operations, the deformation is simulated by imposing successive deformation increments; at each deformation step a set of boundary conditions (either strain rates or a combination of strain rates and stress components) is
Fig. 16 Simple shear VPSC polycrystal plasticity analyses of AA7003-T6 with texture update (left) and without texture update $(r i g h t)$
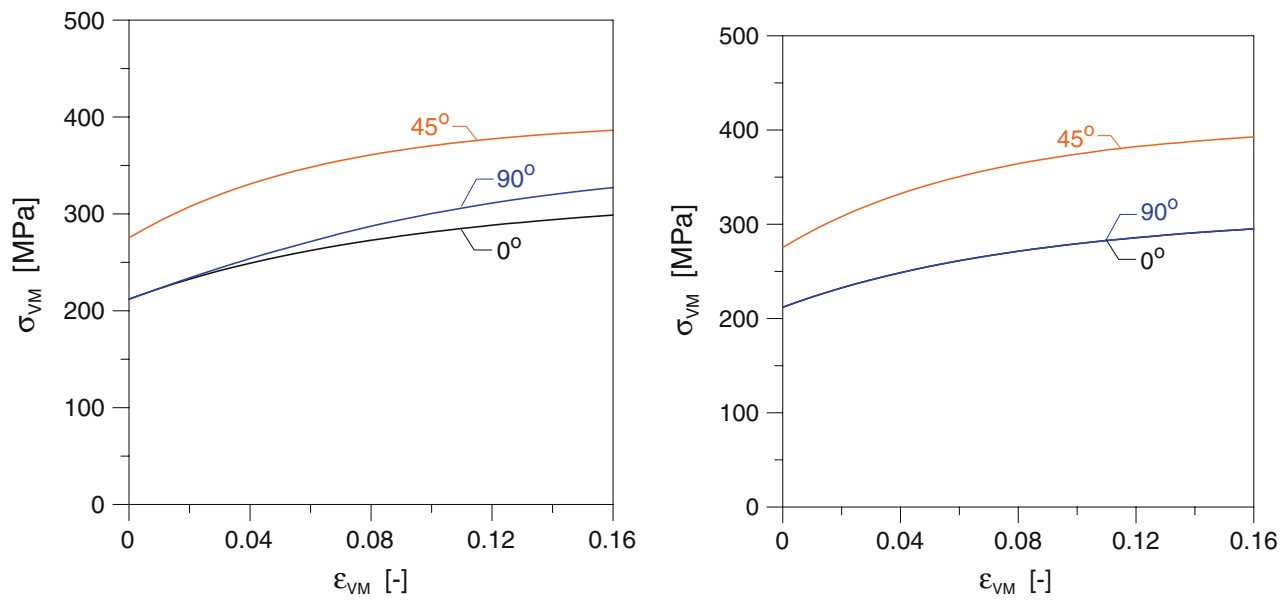
imposed to the (discrete) sheet texture, and the stresses and strain rates in each grain are calculated. The shear rates are used to determine changes in crystallographic orientation and to update grain shape and yield stresses in the individual grains. The overall (macroscopic) stresses and strains follow from averaging over the corresponding grain components. In the present case, the work-hardening parameters of alloy AA7003-T6 were derived by fitting the uniaxial tensile tests in the $0^{\circ}$ direction. The resulting microscopic, i.e. grain-level, work-hardening parameters were then used to simulate shear tests under $0^{\circ}, 45^{\circ}$ and $90^{\circ}$ to the extrusion direction.

For the sake of simplicity, the comparison is performed for simple shear in the plane of the flat profile without any constraints in the ND. The assumption of simple shear implies that secondary normal stresses will develop with straining. Analyses were performed for the directions investigated in the experimental shear tests. Since this deformation condition gives rise to a multiaxial stress state, the comparison is made in terms of equivalent values of the stress and strain tensors. For practical reason, the von Mises equivalent stress and strain are used. To address the effect of texture changes, analyses were performed with and without texture update. The results are provided in Fig. 16. The simulation with texture update exhibits a marked deviation in the equivalent stress for the $0^{\circ}$ and $90^{\circ}$ orientations with straining, in qualitative agreement with the experimental results from the shear tests for this alloy. When the texture is not updated, which is the case in the FE simulations using an anisotropic yield surface with isotropic work-hardening, the two directions show identical behaviour. These results indicate that texture evolution is, indeed, the cause of the deviating response observed for the shear tests in the $0^{\circ}$ and $90^{\circ}$ orientations for AA7003-T6, and further that the assumption of isotropic work-hardening is insufficient to represent the response of the directional shear tests.

\section{Concluding remarks}

The use of plane-strain tension and shear tests in the parameter identification and assessment of constitutive relations for aluminium alloys with strong crystallographic texture has been investigated in this paper. It is found that these tests provide additional information that is useful in the parameter identification. By calibrating the anisotropic yield criterion from uniaxial tension tests in several directions, analytically defined directional stress ratios in plane-strain tension and shear may be calculated. These stress ratios are helpful in identifying an optimum experimental design for the plane-strain tension and shear tests so that these provide as much information as possible on the directional dependence of the yielding in these stress states.
Significant deviations between the experimental and predicted behaviour in plane-strain tension and shear were revealed when using FE simulations and the anisotropic yield criterion Yld2004-18p with isotropic work-hardening. The calibration of the yield criterion and the workhardening rule was solely from uniaxial tension tests in several in-plane directions and a disc compression test in the ND of the flat profile. The deviations are partly caused by the calibration procedure used to determine the anisotropy coefficients and partly caused by the use of isotropic work-hardening. It was indicated how a new and presumably more accurate parameter set could be determined by including the results from the plane-strain tension and shear tests in the identification procedure. The use of isotropic work-hardening led to inaccuracies with respect to the elongation at necking in the plane-strain tension tests and failure to predict deviations in the response in shear tests in the $0^{\circ}$ and $90^{\circ}$ orientations for AA7003-T6. It was suggested by use of polycrystal plasticity calculations that texture evolution is important, at least in shear, and thus the assumption of isotropic work-hardening is not appropriate.

Open Access This article is distributed under the terms of the Creative Commons Attribution Noncommercial License which permits any noncommercial use, distribution, and reproduction in any medium, provided the original author(s) and source are credited.

\section{References}

1. Hopperstad OS, Langseth M, Remseth S (1995) Cyclic stressstrain behaviour of alloy AA 6060 T4, Part II: biaxial experiments and modelling. Int J Plasticity 11:741-762

2. Fjeldly A, Roven HJ (1996) Observations and calculations on mechanical anisotropy and plastic flow of an AlZnMg extrusion. Acta Mater 44:3497-3504

3. Fjeldly A, Roven HJ (1997) Phenomenological modeling of the mechanical anisotropy in AlZnMg extruded profiles. Mat Sci Eng A 234-236:606-609

4. Lademo O-G, Hopperstad OS, Langseth M (1999) An evaluation of yield criteria and flow rules for aluminium alloys. Int $\mathrm{J}$ Plasticity $15: 191-208$

5. Lademo O-G, Hopperstad OS, Malo KA, Pedersen KO (2002) Modelling of plastic anisotropy in heat-treated aluminium extrusions. J Mater Process Technol 125-126:84-88

6. Lademo O-G, Hopperstad OS, Berstad T, Langseth M (2005) Prediction of plastic instability in extruded aluminium alloys using shell analysis and a coupled model of elasto-plasticity and damage. J Mater Process Technol 166:247-255

7. Li S, Engler O, Van Houtte P (2005) Plastic anisotropy and texture evolution during tensile testing of extruded aluminium profiles. Model Simul Mater Sci Eng 13:783-795

8. Reyes A, Hopperstad OS, Lademo O-G, Langseth M (2006) Modeling of textured aluminum alloys used in a bumper system: Material tests and characterization. Comp Mater Sci 37:246-268

9. Hopperstad OS, Berstad T, Ilstad H, Lademo OG, Langseth M (1998) Effects of the yield criterion on local deformations in 
numerical simulation of profile forming. J Mater Process Technol 80-81:551-555

10. Kokkula S, Hopperstad OS, Lademo O-G, Berstad T, Langseth M (2006) Offset impact behaviour of bumper beam-longitudinal systems: numerical simulations. Int J Crashworthiness 11:217-336

11. Lademo O-G, Berstad T, Eriksson M, Tryland T, Furu T, Hopperstad OS, Langseth M (2008) A model for process-based crash simulation. Int J Impact Eng 35:376-388

12. Lademo O-G, Pedersen KO, Berstad T, Furu T, Hopperstad OS (2008) An experimental and numerical study on the formability of textured AlZnMg alloys. Eur J Mech-A/Sol 27:116-140

13. Pedersen KO, Lademo O-G, Berstad T, Furu T, Hopperstad OS (2008) Influence of texture and grain structure on strain localisation and formability for AlMgSi alloys. J Mater Proc Technol 200:77-93

14. Reyes A, Hopperstad OS, Berstad T, Lademo O-G (2009) Prediction of forming limit diagrams for two aluminum alloys under non-proportional loading by using an FE-based approach. Int J Mater Form 1:211-232

15. Hill R (1948) A theory of the yielding and plastic flow of anisotropic metals. Proc Roy Soc London A193:281-297

16. Barlat F, Lian J (1989) Plastic behaviour and stretchebility of sheet metals. Part I: A yield function for orthotropic sheets under plane stress conditions. Int J Plasticity 13:385-401

17. Barlat F, Lege DJ, Brem JC (1991) A six-component yield function for anisotropic materials. Int J Plasticity 7:693-712

18. Karafillis AP, Boyce MC (1993) A general anisotropic yield criterion using bounds and transformation weighting tensor. J Mech Phys Solids 41:1859-1886

19. Barlat F, Maeda Y, Chung K, Yanagava M, Berm JC, Hayashida Y, Lege DJ, Matsui K, Murtha SJ, Hattori S, Becker RC, Makosey S (1997) Yield function development for aluminium alloy sheets. J Mech Phys Solids 45:1727-1763

20. Barlat F, Brem JC, Yoon JW, Chung K, Dick RE, Lege DJ, Pourboghrat F, Choi SH, Chu E (2003) Plane stress yield function for aluminium alloy sheets-part I: theory. Int J Plasticity 19:12971319

21. Banabic D, Kuwabara T, Balan T, Comsa DS, Julean D (2003) Non-quadratic yield criterion for orthotropic sheet metals under plane-stress conditions. Int J Mech Sci 45:797-811

22. Cazacu O, Barlat F (2003) Application of the theory of representation to describe yielding of anisotropic aluminium alloys. Int J Eng Sci 41:1367-1385

23. Aretz $H$ (2004) A non-quadratic plane stress yield function for orthotropic sheet metals. J Mater Proc Technol 168:1-9
24. Barlat F, Aretz H, Yoon JW, Karabin ME, Brem JC, Dick RE (2005) Linear transformation based anisotropic yield functions. Int J Plasticity 21:1009-1039

25. Achani D, Hopperstad OS, Lademo O-G (2009) Behaviour of extruded aluminium alloys under proportional and nonproportional strain paths. J Mater Proc Technol 209:4750-4764

26. Bouvier S, Haddadi H, Levée P, Teodosiu C (2006) Simple shear tests: Experimental techniques and characterization of the plastic anisotropy of rolled sheets at large strains. J Mater Process Technol 172:96-103

27. Aretz H, Hopperstad OS, Lademo O-G (2007) Yield function calibration for orthotropic sheet metals based on uniaxial and plane strain tensile tests. J Mater Proc Technol 186:221-235

28. Reyes A, Eriksson M, Lademo O-G, Hopperstad OS, Langseth M (2009) Assessment of yield and fracture criteria using shear and bending tests. Mater Design 30:596-608

29. Lademo O-G, Engler O, Keller S, Berstad T, Pedersen KO, Hopperstad OS (2009) Identification and validation of constitutive model and fracture criterion for AlMgSi alloy with application to sheet forming. Mater Design 30:3005-3019

30. Engler O, Randle V (2010) Introduction to texture analysis: macrotexture, microtexture and orientation mapping. CRC Press, Boca Raton FL

31. Achani D (2006) Constitutive models of elastoplasticity and fracture for aluminium alloys under strain path change. $\mathrm{PhD}$ Thesis, Deptartment of Structural Engineering, NTNU, ISBN 82471-7903-2.

32. Lademo O-G, Eriksson M, Reyes Aa, Hopperstad OS, Langseth M (2006) Characterisation of failure and identification of failure related parameters, SINTEF report STF80MK F06083 (proprietary).

33. Belytschko T, Liu WK, Moran M (2000) Nonlinear Finite Elements for Continua and Structures. Wiley.

34. Hershey AV (1954) The plasticity of an isotropic aggregate of anisotropic face centred cubic crystals. J Appl Mech 21:241-249

35. Lemaitre J, Chaboche J-L (1990) Mechanics of Solid Materials. Cambridge University Press.

36. LSTC (Livermore Software Technology Corporation), 2003. LSDYNA Keyword User's Manual, Version 970.

37. Lebensohn RA, Tomé CN (1993) A self-consistent anisotropic approach for the simulation of plastic deformation and texture development of polycrystals: Application to zirconium alloys. Acta Metall Mater 41:2611-2624

38. Engler O (2009) Comparison of X-ray and electron backscatter diffraction textures for back-annealed Al-Mg alloys. J Appl Cryst 42:1147-1157 